\title{
Re-refining of used Oil- an Insight
}

\author{
Dr. Sunil Jayant Kulkarni
}

Datta Meghe College of Engineering, Airoli, Navi Mumbai, Maharashtra, India

\begin{abstract}
Energy and environment are two most talked about words by environment activists and organizations. The oil which is used for moving parts and other friction induced machines, in order to reduce friction and save energy becomes contaminated after one use. The reuse of such oil may not give desirable results. Disposing and reuse are two possible alternatives. The disposal of the waste oil has serious environmental foot prints. It is envisaged to reuse the oil as far as possible. Many investigations are reported on reuse of oil and re-refining of used oil. Many methods such as adsorption, dehydration, vacuum distillation, solvent extraction have been investigated for the re-refining of used oil. Current review summarizes research and studies of used oil.
\end{abstract}

Keywords: Disposal, treatment, solvent, adsorption, cracking.

\section{INTRODUCTION}

Any petroleum-based or synthetic oil that has been used is termed as used oil. Cars, lawnmowers, and many other machines are running smoothly due to oil. The oil no longer performs well after certain time. Also disposing oil to the land or water bodies causes serious environmental degradation. Adsorption is one of the important method for recovery [1-2]. Already the air and water pollution due to petroleum industries is cause of concern. Investigations are being carried out for wastewater treatment of petroleum industries.[3-5].Many investigations are directed towards enhanced oil recovery[7-9]. It is observed that, during normal use, impurities such as dirt, metal scrapings, water, or chemicals, can get mixed in with the oil. Eventually, this used oil must be replaced with virgin or re-refined oil to do the job correctly. The motor oil, which is used once, is insoluble, persistent, and can contain toxic chemicals and heavy metals. Recycling saves a valuable resource as motor oil does not wear out, it just gets dirty.

The oil which is used for moving parts and other friction induced machines, in order to reduce friction and save energy becomes contaminated after one use. The reuse of such oil may not give desirable results. Disposing and reuse are two possible alternatives. The disposal of the waste oil has serious environmental foot prints. It is envisaged to reuse the oil as far as possible. Many investigations are reported on reuse of oil and re-refining of used oil. Many methods such as adsorption, dehydration, vacuum distillation, solvent extraction have been investigated for the re-refining of used oil. In the current review, research and studies on reuse of used oil are summarized.

\section{AN INSIGHT INTO RE-REFINING OF USED OIL}

Kannan et.al. investigated the possibilities of reuse of used automotive lubricating oil[10].Rerefining of used oil serves many purposes. The used oil when disposed to land causes various problems including groundwater contamination. The burning of this used oil produces the combustion products, which are highly polluted with undesirable gases. The re-refining is the best possible solution to all these problems. In their research, they used the acid clay treatment process. In this process used oil is treated with strong acid and then clay. To this method, they an alternative method that is ecofriendly and produces good quality refined oil. The new method included dehydration, vacuum distillation followed by solvent extraction. Atmospheric distillation can be used for refinement of solvent. Also they determined properties such as density, viscosity, viscosity index, flash point, fire point, pour point, cloud point and total acid number. These properties after re refining were well within the SAE standards.

Nasim et.al. reviewed waste oil as a fuel for diesel engines with various microwave pyrolysis applications in waste to energy engineering [11]. Factors such as energy demand, stringent emission 
norms and depletion of oil resources are driving forces for waste oil recycling. Also, according to them, waste oils pose a very serious environment challenge. According to them, waste oil as a fuel for diesel engines with various microwave pyrolysis applications is one of the possible solutions to energy and environmental problems. The energetic and chemical value of the waste materials can be reestablished with the pyrolysis process. They carried out studies for effect of diesel-like fuel (DLF) on engine performance and exhaust emission. Their research also indicated that, thermal and physical characteristics of the DLF were close to those values of a typical diesel sample. Diphare et.al. compared various waste lubricating oil treatment techniques[12].They discussed techniques such as reprocessing, re-refining and incineration of waste lubricating oil. According to their studies, pretreatment by heat or filtration, followed by either vacuum distillation with hydrogen finishing or clay, or solvent extraction with clay and chemical treatment with hydro-heating are commonly employed techniques for re-refining of used oil. When oil is contaminated with polychlorinated biphenyl (PCB) and polychlorinated terphenyls (PCT), controlled high-temperature incineration at cement factories can be useful. The temperature in excess of $2000 \mathrm{C}$ is sufficient to destroy organics and neutralize acid compounds. According to them, re-refining is the most effective technique which renders the viscosity close to original oil.

Kannan and Saravanan explored use of Waste engine oil (WEO) as fuel for the catalytic fuel reformer (CFR)[13].They used alumina as catalyst for cracking the waste oil. For the waste engine oil in the form of condensed reformulated condensed fuel was analyzed for specific gravity, kinematic viscosity, flash and fire point, gross calorific value, pour point, density. They found that all the properties closer to that of diesel fuel. Danane et.al. carried out investigation on regeneration of used motor oils[14]. They identified the different stages of the process of regeneration by comparative analysis between the sample taken from a storage tank and new engine oil. Their process included pretreatment, metal removal by chemical agents, finishing and filtration. Due to elimination of carbonaceous materials and volatile compounds, there was improvement of flow point and flash point. They concluded that a finished engine oil was having highly improved characteristics was close to that of the base oil.

Udonne carried out investigation on recycling of used lubrication Oils[15]. His studies were focused on comparative study of four methods of recycling of used lubrication oils: acid/clay treatment, distillation/clay, acid treatment and activated charcoal/clay treatment methods. He carried out studies on properties such as flash point, pour point, specific gravity, metal contents, viscosity and sulphur contents. His investigation indicated that viscosity increased from 25.5 for used lube oil to 86.2 for distillation. It increased to 89.10 for acid/clay treatment. For activated clay treatment this value was slightly low, 80.5 percent. Jhanani and Joseph investigated oil generation and management in the automotive industries for efficient use of oil [16]. They studied oil generation and management practices by the automotive industries in Tamilnadu. They studies oil management practices. They found that few industries use centrifuges, electrostatic liquid cleaners, magnetic separators etc. for oil management. They also studies oil samples collected on two different days from one of the automotive industry. They found that the machining activities like cutting and drilling constitutes $85 \%$ of the used oil generation in the automotive sector. According to them, 50\% of used oil generation could be reduced by efficient reuse of the oil before disposal.

Mekonnen and Yimam carried out detailed studies on Acid-Clay Treatment Process for Recycling of Used Lubricating Oil[17].They carried out investigation with Recycling experiments 15, 20 and 25\% acid and adsorbent (Bentonite clay) ratios with different combinations. They obtained 55\% to $74.7 \%$ yield during their investigation. They observed that acid percentage of $20 \%$ and adsorbent percentage of $15 \%$ were optimum conditions. DeDene and You carried out studies on the ability to recycle large amounts of asphalt pavement[18].They used Waste engine oil from automobiles to improve asphalt binder.Their study shwed that waste engine oil has the ability to chemically restore aged asphalt binder. Zitte et.al. carried out an investigation on used-oil generation and its disposal[19].They found the absence oil treatment mechanism. Their survey indicated that there was only thirty percent have the awareness of used-oil recycling. They emphasized the need for awareness regarding oil treatment and reuse. Also there was a need of strong legal framework to implement reuse policy. Emam and Shoaib compared two different processes for refining of waste oil[20].They established laboratory scale set up for solvent extraction/clay and acid/clay-percolation processes.Also they compared virgin base oil and with standard regeneration lubricating oil characteristic. They observed $0.42 \mathrm{wt} \%$ and $0.81 \%$ sulphur content for acid/clay-percolation and solvent/clay. Isah et.al. carried out investigation 
on regeneration of used engine oil using industrial bleaching earth and activated carbon as the bleaching agents[21].They found that bleaching earth exhibited better bleaching properties than activated carbon.

\section{CONClusion}

Recycling saves a valuable resource as motor oil does not wear out, it just gets dirty. The oil which is used for moving parts and other friction induced machines, in order to reduce friction and save energy becomes contaminated after one use. The reuse of such oil may not give desirable results. Disposing and reuse are two possible alternatives. The disposal of the waste oil has serious environmental foot prints. It is envisaged to reuse the oil as far as possible. Many investigations emphasize that the used oil when disposed to land causes various problems including groundwater contamination. The burning of this used oil produces the combustion products, which are highly polluted with undesirable gases. Most of investigations suggested that, the re-refining is the best possible solution to all these problems.

\section{REFERENCES}

[1] Reza Behnood, Bagher Anvaripour, Nematollah Jaafarzade Haghighi Fard and Masoumeh Farasati,2013, "Application of Natural Sorbents in Crude Oil Adsorption”, Iranian Journal of Oil \& Gas Science and Technology, 2(4), PP. 01-11.

[2] Nabil M. Abdel-Jabbar, Essam A.H. Al Zubaidy, and Mehrab Mehrvar,2010,"Waste Lubricating Oil Treatment by Adsorption Process Using Different Adsorbents", International Journal of Chemical and Biological Engineering, 3(2), PP.70-73.

[3] H.A. Gasim, S.R.M. Kutty, M. Hasnain Isa and L.T. Alemu(2013),"Optimization of Anaerobic Treatment of Petroleum Refinery Wastewater Using Artificial Neural Networks", Research Journal of Applied Sciences, Engineering and Technology, 6(11), PP.2077-2082.

[4] Basheer Hasan Diya,, Uddeen, Wan MohdAshri Wan Daud, A.R. Abdul Aziz(2011), "Treatment technologies for petroleum refinery effluents:A review", Process Safety and Environmental Protection, 89, PP. 95-105.

[5] Sergio A. Martínez-Delgadillo, Miguel A. Morales-Mora and Icela D. Barcelo-Quintal(2010), "Electrocoagulation Treatment To Remove Pollutants From Petroleum Refinery Wastewater", Sustain. Environ. Res., 20(4), PP.227-231.

[6] Sunil Jayant Kulkarni, "An Insight into Oil and Grease Removal from Wastewater from Petroleum and Refinery Industries", International Journal of Petroleum and Petrochemical Engineering (IJPPE), 2(1), PP. 12-15.

[7] KarovicMaricicVesna, LekovicBranko, DanilovicDusan, 2014, "Factors Influencing Successful Implementation Of Enhanced Oil Recovery Projects", Underground Mining Engineering, 25, PP. 41-50.

[8] Abubaker H. Alagorni, Zulkefli Bin Yaacob, and Abdurahman H. Nour, 2015, "An Overview of Oil Production Stages: Enhanced Oil Recovery Techniques and Nitrogen Injection", International Journal of Environmental Science and Development, 6(9), PP.693-702.

[9] Sunil Jayant Kulkarni, 2017, "An Insight into Research and Studies on Enhanced Oil Recovery (EOR) In Petroleum Industries", International Journal of Petroleum and Petrochemical Engineering (IJPPE), 3(2), PP. 1-4

[10] ShriKannan C, Mohan Kumar KS, Sakeer Hussain M, DeepaPriya N and Saravanan K, 20144, “ Studies on Reuse of Re-Refined Used Automotive Lubricating Oil", Research Journal of Engineering Sciences, 3(6), PP.8-14.

[11] Mohd. NematullahNasim,M. SohailPervez, Ravindra BabuYarasu, Namrata V Lotia,2014, "Recycling waste automotive engine oil as alternative fuel for diesel engine: A Review", IOSR Journal of Mechanical and Civil Engineering, 1, PP.46-50.

[12] Motshumi J. Diphare, Edison Muzenda, Tsietsi J. Pilusa and Mansoor Mollagee, 2013, "A Comparison of Waste Lubricating Oil Treatment Techniques", 2nd International Conference on Environment, Agriculture and Food Sciences (ICEAFS'2013) August 25-26, 2013 Kuala Lumpur (Malaysia),1, PP.106-109. 
[13] M. Kannan and Dr. C.G. Saravanan, 2014, "Characterization of alumina catalyst in the catalytic fuel reformer", American International Journal of Research in Science, Technology, Engineering \& Mathematics, 7(2), PP. 127-131.

[14] F. Danane, A. Ahmia 2, A. Bakiri and N. Lalaoui, 2014, "Experimental regeneration process of used motor oils, Revue des Energies Renouvelables , 17(2), PP.345 - 351.

[15] Udonne J. D.,2011, “ A comparative study of recycling of used lubrication Oils using distillation, acid and activated charcoal with clay methods", Journal of Petroleum and Gas Engineering, 2(2), PP. 12-19.

[16] Jhanani. S ,KurianJoseph,2011,"Used oil generation and management in the automotive industrie s”, International Journal Of Applied Engineering Research, Dindigul , 2(1), PP.135-146.

[17] Hayalu Andargachew Mekonnen, Ing. Abubeker Yimam,2014, "Recycling of Used Lubricating Oil Using Acid-Clay Treatment Process", Addis Ababa University Addis Ababa Institute Of Technology (Aait) School Of Chemical And Bio-Engineering (MSc. Program in Environmental Engineering),1, PP.1-80.

[18] Christopher D. DeDene and Zhanping You, 2014, "The Performance of Aged Asphalt Materials Rejuvenated with Waste Engine Oil”, Int. J. Pavement Res. Technol., 7(2), PP.145-152.

[19] Zitte LF, Awi-Waadu GDB and Okorodike CG, 2016, "Used-Oil Generation and Its Disposal along East-West Road, Port Harcourt Nigeria", Int J Waste Resour, 6(1), PP.1-5.

[20] Eman A. Emam, Abeer M. Shoaib, 2012, "Re-refining of Used Lube Oil, II- by Solvent/Clay and Acid/Clay-Percolation Processes", ARPN Journal of Science and Technology, 2(11), PP.10341041.

[21] Isah, A. G., Abdulkadir, M., Onifade, K. R., Musa, U., Garba, M. U., Bawa, A. A and Sani, Y., 2013, "Regeneration of Used Engine Oil", Proceedings of the World Congress on Engineering 2013 Vol I, WCE 2013, July 3 - 5, 2013, London, U.K., PP. 1-4.

\section{AUTHOR's BIOGRAPHY}

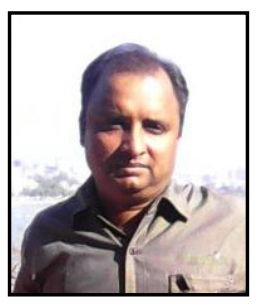

Dr. Sunil J. Kulkarni, has completed his Masters in Chemical Engineering from Tatyasaheb Kore Institute of Engineering and Technology, Warananagar in 2006. $\mathrm{He}$ haspursued his Ph.D in chemical engineering. He is working as Assistant Professor in Chemical Engineering Department of Datta Meghe College of Engineering, Airoli, Navi Mumbai, India. The author has 16 years of experience in teaching and research. He has published 200 international review and research papers and presented 15 research papers in international conferences. His area of research includes adsorption, environmental engineering and catalysis. He is editorial board member of more than 25 international journals and reviewed many international papers. 